I Pontifícia Universidade Católica do Rio de Janeiro (PUC-Rio),

Departamento de Educação, Rio de Janeiro, RJ, Brasil

mylenemizrahi@gmail.com

https://orcid.org/oooo-0002-066I-2273

Mylene Mizrahi'

\title{
O QUE A "HUMILDADE DOS OBJETOS" PODE NOS DIZER SOBRE A BELEZA NO RIO DE JANEIRO: NOTAS SOBRE UMA TRAJETÓRIA DE PESQUISA
}

A discussão que diferentes teorias da materialidade propõem soa hoje mais ou menos familiar nas ciências sociais e nas ciências humanas de modo geral. Pesquisas contemporâneas em campos de estudos tão díspares como os da religião e da educação acompanham o que vem sendo chamado de virada material, nomeação que subentende uma certa novidade e radicalidade na mudança, mas que, podemos dizer, é o efeito de leituras críticas em curso desde os anos I980. Tais leituras críticas são passíveis de ser amplamente sintetizadas pelo desmantelar do chamado grande divisor natureza e cultura. Daniel Miller tem uma posição singular nesse debate: ao mesmo tempo em que é figura crucial para o projeto de repensar o lugar que as coisas ocupam na análise social é também reiteradamente acionado em propostas que visam produzir abordagens inovadoras. Esses projetos, ao buscar avançar analítica e conceitualmente no tema, frequentemente tomam como ponto de partida as bases colocadas por Miller, muitas das vezes sugerindo que o antropólogo britânico poderia ter ido mais longe no processo de fazer das coisas entrada analítica de pesquisa.

Podemos assim dizer que Miller aglutina, seja por meio de suas próprias pesquisas, seja por meio das leituras que elas suscitam, muitos dos caminhos que o tema da materialidade vem traçando. Miller pode ser, portanto, tomado como um nó que articula essas muitas teorias, ao mesmo tempo em que se mantém firme naquilo que delas o diferencia. Esse poder articulador, a meu ver, deriva, de um lado, de sua habilidade de produção e manutenção de cone- 
xões, o que se traduz na generosidade para com seus alunos e colaboradores, e, de outro, de sua defesa incondicional da etnografia como prática distintiva do modo antropológico de proceder à produção de conhecimento. Como o autor explicita na introdução a Materiality (Miller, 2005), é a etnografia que garante que sejamos humildes não somente na relação com os objetos materiais, mas em nossas elaborações teórico-conceituais, prevenindo-nos no campo das vaidades e da armadilha fácil de pensar que estamos "reinventando a roda".

É assim acompanhando a generosidade analítica e afetiva de Miller que atendo ao convite dos editores desta edição. Escrever algumas páginas sobre a relação entre a minha trajetória/obra e a teoria/obra/trajetória dele envolve retomar, mesmo que brevemente, as muitas teorias da materialidade que sigo explorando em meu percurso intelectual e acadêmico, que teve por cerne uma investigação da criatividade junto ao funk carioca. Farei isso passando por minhas diferentes pesquisas: sobre o figurino funk, que emergiu em minha dissertação de mestrado; sobre a estética funk carioca, que conceituei em minha tese de doutorado; aquela relativa aos cabelos negros, com os quais elaborei conceitualmente sobre problemas levantados nas pesquisas anteriores. Em minha trajetória de pesquisa tenho por suporte analítico a criação musical, o corpo e as materialidades. Aqui darei ênfase às estéticas corporais para com elas revisitar o encontro com Daniel Miller.

Voltemos ao que aludi como sendo a posição singular que Miller ocupa no campo de discussão que se instituiu em torno das materialidades e que diz respeito ao estatuto ontológico dos objetos materiais. Miller se aproxima de autores como Alfred Gell em suas propostas de formular abordagens não "linguágicas" para os objetos. Ao mesmo tempo, ele se afasta de tais abordagens ao defender que o rendimento analítico dos objetos reside precisamente em sua diferença ontológica dos seres humanos. Em uma palavra, da perspectiva de Miller, os objetos oferecem rendimento analítico, são produtivos analiticamente, justamente ao ser conceituados como ontologicamente diferenciados dos seres humanos. O que nos leva a uma formulação preciosa sua, aquela relativa à "humildade dos objetos", com a qual o antropólogo nos remete ao modo silencioso com que a forma material nos ordena enquanto pensamos que somos nós que a ordenamos (Miller: 1987).

Tal formulação parece-me preciosa porque a noção de "humildade dos objetos" reitera o próprio fato de que as coisas estão lá quietas enquanto somos nós, humanos, a agir. Ao mesmo tempo, a formulação de Miller abre para a possibilidade de tomarmos as coisas como se agindo sobre o mundo. Um agir que defensores mais apaixonados de Alfred Gell e também de Bruno Latour dirão ser conceitualmente muito diferente da noção de agência social, com a qual ambos os autores elaboraram sobre os efeitos das coisas na vida social. Mas que nos permite aproximar os três - Miller, Gell e Latour - se consideramos a crítica auspiciosa feita por Tim Ingold (2012) à noção de agência. Como nota 
este último autor, a ideia de "agência dos objetos" produz como enquadramento necessário concebermos as coisas como incondicionalmente inanimadas, sem vida. Dependem para agir, outrossim, das instâncias humanas, que seriam, estas sim, as reais detentoras de agência. Tal separação é acionada de modo evidente por Miller na formulação de sua teoria da materialidade. Podemos, entretanto, encontrá-la também na concepção de Gell (I998) de que os objetos de arte são agentes secundários e distribuem a agência primária que tem por origem a mente criativa humana. Igualmente, a ação social que se institui na rede de mediadores, como conceituada por Latour (2005), pressupõe como condição necessária a presença de instâncias humanas que, em interação com as não humanas, produzirão eventos. ${ }^{\mathrm{I}}$

Seja como for, a noção de "humildade dos objetos" veio ao encontro de minha própria posição de antropóloga interessada no rendimento que os discursos em torno da estética adquirem para a análise social, me permitindo escapar às disputas do campo. Pois se chego a Miller a partir de meus interesses nos usos e significados atribuídos aos bens de consumo, chego às materialidades por meio de uma discussão própria à antropologia da arte, como colocada por Els Lagrou (2007), que toma como ponto de partida as proposições de Gell a fim de propor caminhos para uma dessubstancialização do objeto. Foi assim que articulei as formulações de Miller à proposta de uma antropologia da arte, como colocada por Gell, que buscava resgatar o laço entre forma e função, rompido pela noção de estética universal. Tratava-se de reconceituar a estética com meus amigos funk. A "humildade dos objetos" e os discursos sutis, mas não menos políticos, produzidos pela estética estiveram lado a lado.

A atenção ao caráter humilde dos objetos se afinou a uma abordagem da estética conduzida pelo acompanhar de seus discursos silenciosos. Foi assim que conciliei uma abordagem que aposta no potencial de diferenciação ontológica entre pessoas e coisas com as proposições dessubstancialistas de Lagrou e a coloquei em diálogo com perspectivas usualmente tomadas como antitéticas àquelas epitomizadas por Miller, tanto as relativas aos sistemas classificatórios de bens (Lévi-Strauss, I989; Sahlins, 2003; Bourdieu, I984) quanto as abordagens que defenderam um uso heurístico das coisas na pesquisa antropológica (Henare, Holbraad \& Wastell, 2007). A chave para tal liberdade adquiri não somente por meio de minha formação teórica e conceitual, desde o início norteada pelo mundo dos objetos, mas pelo treino igualmente fundamental na etnografia, fundeado no reconhecimento da centralidade que a condução de um trabalho de campo sistemático e intensivo apresenta para a antropologia.

É, portanto, a partir da articulação das diferentes abordagens da materialidade que imprimi ao longo de minha trajetória de pesquisa que estabeleço minha relação de colaboração com Miller. Voltemos a ela.

Minha pesquisa de mestrado se desenrolou majoritariamente no baile funk que ocorria nas noites de sábado e vésperas de feriados em um clube 
no Centro da cidade do Rio de Janeiro. Ao longo de 18 meses acompanhei rapazes e moças na festa e em suas produções anteriores a esta, fazendo incursões a residências, locais de trabalho, centros de compras e embelezamento.

Cheguei ao baile com o intuito de testar hipóteses levantadas em pesquisa anterior (Mizrahi, 2003). Interessava-me acompanhar os discursos verbais e não verbais das usuárias de um estilo de calças femininas que até então eu designara como do segmento jeans. No baile constatei que o que eu conhecia por meio da categoria midiática "calça da Gang", fazia parte de um estilo cultural englobante designado pela categoria nativa "calça de moletom stretch". A categoria nativa, ao nomear o estilo, desvinculava-o de um produtor particular, a empresa Gang, ao mesmo tempo em que o designava como expressão da criatividade cultural. Além disso, e talvez mais importante para o meu ponto aqui, fazia uma ponte imediata com o tecido empregado na sua produção. Em vez do criador individual, como expresso por meio da categoria midiática, o que definia o estilo no baile era a sua materialidade.

Mas as qualidades intrínsecas do objeto só poderiam ter seu significado acessado a partir da consideração do corpo que a vestia: um corpo específico em uma dança também específica. Foi assim que adentrar um mundo funk a partir dos resultados de uma pesquisa em torno da ressignificação da calça pelo discurso midiático levou-me a produzir uma etnografia do baile com base em seus elementos estéticos, tomando-o como um todo (Mizrahi, 20Igb).

Se parecia ser um jeans, a referida calça era na verdade um simulacro seu, feito em moletom stretch: uma malha de algodão mesclada ao fio de elastano, a lycra, que após tinturada e lavada poderia adquirir a aparência de jeans. As propriedades do tecido tornavam-no extremamente elástico, aderente ao corpo e confortável. Enquanto o jeans stretch resulta de um tecido plano mesclado ao elastano e essa qualidade faz com que ele estique somente em sua largura, o moletom stretch é tecido circular que, por definição, estica na largura e altura, e se torna ainda mais elástico ao ser mesclado ao fio de elastano. Além disso, sua espessura suporta uma série de ações embelezadoras, como apliques de cristais, tacheados, rendas, perfurações, concedendo ares barrocos à peça de roupa e tornando-a ainda mais apropriada para a festa.

A calça permitia liberdade de movimentos a um corpo em dança que realizava movimentos circulares e realçava um corpo feminino todo ele redondo e voluptuoso. Ela expressava, portanto, não apenas um estilo, mas o tipo de corpo valorizado, o gosto indumentário, a noção de feminino e, por contraste, seus correlatos masculinos. Foi essa pesquisa que provocou meu encontro com Miller e me levou a Londres para fazer meu doutorado-sanduíche sob sua supervisão, dessa vez com outro projeto de investigação: o relativo à estética funk carioca, que conduzi junto à rede de relações do cantor de funk carioca Mr. Catra, ao longo de outros I8 meses de trabalho de campo (Mizrahi, 2014). 
Em 2006, no início do curso de doutorado e já com minha dissertação defendida, fui apresentada a Miller por uma colega, Carla Barros, em um congresso sobre consumo que aconteceu no Rio de Janeiro, no qual exporíamos nossas pesquisas. Miller, na época, montava uma rede global de pesquisadores sobre os diferentes usos e sentidos do jeans pelo mundo, e ficou muito instigado com meu material, especialmente após observá-lo in loco. Aproveitando sua passagem pelo Rio organizei com Els Lagrou um workshop para os alunos do PPGSA-IFCS-UFRJ, mas não pude deixar de levá-lo ao baile em que conduzi a pesquisa de mestrado, o que lhe rendeu uma noite e tanto!

A materialidade da calça permitia conciliar um corpo e gosto não hegemônicos ao gosto global, epitomizado pelo jeans, e foi a partir desses tensionamentos que elaborei meu subprojeto para o Global Denim Project, coordenado por Miller, e o capítulo para a coletânea de mesmo nome, organizada por ele e por Sophie Woodward, com o qual sintetizei os muitos sentidos que a calça me permitiu desvendar (Mizrahi, 20I I).

Passei seis meses em Londres, participando do grupo de pesquisa coordenado por Miller, que tinha por dinâmica nos reunir na casa de algum orientando seu. Para uma dessas ocasiões, Daniel sugeriu que realizássemos nosso encontro em Brighton, na casa de um ex-aluno, já sediado como professor na Universidade de Sussex. Seria uma boa oportunidade, disse-me Miller, para que eu conhecesse a popular cidade litorânea.

Nesses encontros, quem geralmente cozinhava ou dava as diretrizes do cardápio era o dono da casa, quase sempre um estrangeiro, o que trazia surpresas interessantes, afinadas com o espírito multicultural londrino. Só após termos comido um pouco e bebido outro tanto é que apresentávamos os resultados de nossas pesquisas, o que em nada reduzia o rigor do debate. Ao contrário, nesses encontros pude experimentar o modo agonístico com que o debate intelectual é conduzido no ambiente acadêmico britânico.

Essas reuniões de discussão de resultados de pesquisa e as muitas apresentações de trabalho que fiz em congressos e seminários contribuíram para que eu deixasse Londres com o argumento de minha tese estruturado. Argumento que, é preciso dizer, causou certo estranhamento em Miller, por meu foco privilegiado na pessoa do artista, mais do que na "cultura". Foi, porém, em uma última conversa de orientação, em um pub próximo à UCL (University College London), que Miller generosamente me falou de sua admiração por meu trabalho, que renderia ainda, cinco anos depois, a quarta capa do livro com o qual publiquei minha tese de doutorado.

Se no mestrado adentrei o mundo funk por meio da festa e de seus fruidores, desvendando os sentidos de um estilo cultural, no doutorado, ao me deter sobre a produção do universo de relações erigido em torno de um movimento musical, voltei-me para a pessoa do artista. "Esqueci" assim a calça, para parafrasear processo análogo por meio do qual Els Lagrou deslocou, mo- 
I050

mentaneamente, o foco em sua investigação de doutorado. Passei a me dedicar especialmente à criação e à circulação da música, junto ao coletivo de artistas articulado em torno de Mr. Catra.

Os objetos, contudo, estiveram sempre ali, alguns mais silenciosos do que outros. Meu interesse sobre eles se mantinha e volta e meia eu fotografava um chinelo Havaiana, uma joia em ouro, uma tatuagem, uma bateria eletrônica, um maço de dinheiro. Meus interlocutores em campo achavam esses momentos sempre um tanto curiosos, e eu seguia em minha exploração. Interessante aqui, entretanto, é o fato de que o "objeto" que se mostrou realmente significativo na pesquisa de doutorado foi aquele para o qual eu mesma não atentei, os cabelos femininos. Se no campo de mestrado foram os objetos em sua ostensividade que me guiaram na exploração da corporalidade no baile - a barroca calça de moletom stretch das moças e os cabelos artefatuais, coloridos, descoloridos, raspados e recortados, dos rapazes - no doutorado foi a sua ubiquidade que se mostrou reveladora. Ubiquidade, deve-se notar, igualmente cara a meu supervisor em Londres (Miller \& Woodward, 2007).

Em uma tarde cheguei ao estúdio de gravação que reunia o coletivo de artistas articulado em torno de Mr. Catra e encontrei-o inativo. Os músicos tinham passado a noite acordados, realizando performances pela cidade com vias a cumprir a agenda profissional do coletivo. Todos dormiam, exceto Mr. Catra que, "acostumado com o ritmo", já tinha saído. Dirigi-me então à casa da família, contígua ao estúdio, e me deparei com Silvia, a esposa do artista, não muito disposta para conversas. Thamyris, a filha mais velha, se arrumava para sair com Cida, ex-cunhada de Silvia e que naquele período vinha realizando serviços domésticos na casa da família. Eu pensei comigo que o melhor que eu teria a fazer seria ir embora também, mas, antes de minha partida, Silvia sugeriu que eu desse carona para Thamyris e Cida. Eu respondi que sim, claro, comentando que iria para o Leblon e poderia deixá-las em algum ponto que lhes parecesse conveniente. Silvia, com sarcasmo, disse que "de nada adianta quem vai para o Leblon oferecer carona para quem está indo para Madureira". Seu comentário me desconcertou e ao perceber que as duas não iriam mais comigo, pois minha carona de nada prestava mesmo, decidi mudar de rumo e levar Thamyris e Cida para Madureira.

Os cabelos femininos estiveram sempre à minha volta. Desde o mestrado, ouvi conversas em torno deles e já na pesquisa de doutorado presenciei, em visitas à casa da família, eventos de colocação de extensões de cabelos. Mas foi só após essa minha primeira incursão ao salão de Madureira, propiciada pelas provocações de Silvia, que passei de fato a atentar para eles. Para tal, contribuiu ainda uma outra tarde, seguinte a essa.

Estávamos Silvia, Thamyris e Tó, amiga da família e que igualmente realizava serviços domésticos eventuais na casa, e eu, sentadas descontraidamente na sala de estar. Conversávamos amenidades com a televisão ligada, e 
aproveitei para trazer à baila o tema dos cabelos, que tanto tinha me mobilizado na semana anterior. Comentei sobre o fato de ainda não ter atentado para sua importância e sobre minha vontade de olhar sua produção mais de perto. Silvia e Thamyris se entreolharam e fizeram um comentário jocoso sobre a pouca velocidade com que dirigi na outra tarde. De fato, eu dirigia em velocidade baixíssima ao longo desses deslocamentos, pois precisava conciliar a atenção na estrada com a atenção nas conversas que mantínhamos dentro do carro.

Tó, quase saltando, se levanta do sofá e enfatizando seus gestuais, fala com firmeza: “o cabelo é a coisa mais importante mapoa!". De nada valia um "corpão" sem cabelos, disseram, e acrescentaram que se eu ainda não atentara para os cabelos era porque os tinha. Em outros termos, eu, uma mulher branca, não poderia sozinha notar a importância dos onipresentes cabelos femininos, pois eles não tinha para mim o significado que adquiria para elas. O silêncio dessa onipresença, porém, revelar-me-ia ainda muitos e muitos significados. Como disse-me Thamyris quando decidi levar a sério seus discursos em torno dos cabelos, parecia que eu estava vendo um novo mundo. E estava mesmo.

$O$ adensamento da discussão sobre os cabelos gerou uma série de desdobramentos conceituais levados adiante em minha pesquisa de pós-doc e foram acompanhados de um refinamento da noção de corpo artefatual colocada na tese. Tais desdobramentos, concretizados por meio de quatro diferentes artigos, estiveram sempre em diálogo com as discussões sobre a materialidade como colocadas por Miller, ainda que em cada um deles eu privilegiasse a interlocução com um par de autores diferentes. O rendimento conceitual que os cabelos apresentaram reiteraram o rendimento analítico da noção de "humildade dos objetos".

Os cabelos ambíguos, como denominei o estilo cuja produção acompanhei com Thamyris, Cida, Tó, Silvia, entre outras, condensam de modo ímpar a maneira pela qual as coisas e a estética podem ser loquazes em seu silêncio. Cabelos nem lisos, como os das brancas, mas tampouco crespos, como os afros ou black. Cabelos com os quais minhas amigas buscavam fluidez por meio da aparência, fazendo da ambiguidade racial agência, muitas vezes produzidos por extensões de cabelos humanos, caros e trabalhosos em sua realização. Por meio desses cabelos e da articulação entre beleza, poder de compra e raça, minhas amigas subvertiam a sobreposição de raça e classe que se instituiu no Brasil (Mizrahi, 20I5).

Ao acompanhar a produção dos cabelos femininos vi as mulheres produzirem-se como um em si, ao menos no que tocava à relação com os homens. E se, para estes, chegar a uma festa enlaçando com cada um de seus braços uma mulher era o que causava um "baque", para as mulheres, diferentemente, o homem cumpria o papel de secretário, motorista, segurança. Nesse mundo funk, muitas vezes representado como machista e misógino, cercar-se de mui- 
tas mulheres fala também de uma fragilidade da condição masculina que se faz necessariamente na relação com muitas mulheres, aspecto que evidencio a partir do vai e vem de dinheiro, joias, uísques e mulheres, permitindo complexificar a representação do feminino como submisso aos desejos do homem (Mizrahi, 20I8). Pois a relacionalidade da pessoa feminina residia não em sua contraparte masculina, mas na relação com a mulher branca. Uma disputa que era vivenciada junto aos cabelos.

Se a aparência se mostrava fundante para a produção da pessoa feminina funk, o cabelo adquiriu de fato lugar privilegiado nesse processo. Era para os cabelos que toda entrada extra de dinheiro era invariavelmente destinada. Ao longo desses anos de relação com essas mulheres, em duas ocasiões me pediram dinheiro: uma vez para colocar cabelos; na outra vez o caso era de doença grave. E não foram apenas os marcadores sociais de diferença que foram trazidos à tona pelos cabelos ambíguos, mas a urgência de pensar a produção do self por meio do repensar do corpo.

Com a noção de prótese, como explorada por Marilyn Strathern (I99I: 76) - coisas que são da pessoa e mais do que a pessoa - e a noção de actant de Bruno Latour (2005) - o coletivo formado por flesh, materialidades e pessoa adensei a ideia de um corpo artefatual. Um corpo cujo dado biológico não era mais suficiente para o definir e que permitia pensar na pessoa como produzida de modo fluido, processual. Um self que busca escapar às representações e às cristalizações e que agencia sua aparência de modo a facilitar sua circulação pelo espaço da cidade (Mizrahi, 20I2, 20I5). Com seus cabelos minhas amigas apostavam na dimensão protética da materialidade, refaziam a conectividade produzida pelos homens por meio da música.

E se Judith Butler (I993) argumenta que o gênero é o resultado não estabilizado de uma série de efeitos de performances, aliei à "materialidade dos corpos", a "materialidade dos objetos", como inaugurada por Miller. Expandi assim a noção de performatividade de gênero, como formulada por Butler, para pensar não apenas na produção da pessoa, mas para igualmente colocar a possibilidade de pensarmos a raça como performativa (Mizrahi, 20I9a). As mulheres foram tomadas em sua potência criativa, como artistas no sentido amplo do termo.

Adentrei o universo popular carioca de uma maneira muito peculiar, por meio dos objetos materiais e mais especificamente da indumentária e da moda em uma época em que esses não eram temas correntes nas ciências sociais. A centralidade analítica que as materialidades adquiriram em minha pesquisa de mestrado foram deslocadas em minha prática investigativa de doutorado. Passei a fazer da estética minha entrada conceitual e analítica, seguindo as coisas em sua significação, o que se desdobrou em dois eixos de pesquisa fundamentais: a criação e a subjetivação artística e as estéticas corporais.

Minha pergunta ampla passou a se referir à produção artística, à criatividade, em suma, à produção estética. E foi no processo de perguntar pela es- 
tética - estivesse ela nas formas visuais, sonoras ou artefatuais (Mizrahi, 2007) - que novamente as relações raciais e de gênero retornaram. Friso que meu ponto de partida não foi raça e gênero, mas a atenção à estética, mais especificamente às estéticas corporais e aos cabelos, que colocaram os marcadores sociais de diferença como urgentes. Os cabelos ambíguos mostraram um estilo particular de lidar com o racismo e os preconceitos de classe, um modo silencioso de fazê-lo, o que me levou a ampliar o escopo de minha pesquisa com os cabelos femininos, para além do contexto relacional funk. Passei a conversar com jovens universitárias negras para explorar cabelos que encerram modos mais explícitos de lidar com essas mesmas clivagens, como os afros ou as extensões de cabelos sintéticos coloridos.

Atentar para as materialidades e para a estética me conduziu incialmente às relações de gênero, mais adiante às relações raciais e por fim a um repensar do corpo. Comecei assim minha trajetória de pesquisa a partir de um foco analítico sobre as materialidades, depois deixei esse foco de lado, repousando, até que o próprio campo me levou de volta a ele. O que me permitiu ainda propor tomarmos o consumo como prática criativa, por meio do qual o sujeito se produz e faz ver ao mundo como o entende e se entende nesse mesmo mundo. O consumo pode ser assim um insumo na produção de si, feita essencialmente por meio do corpo e da aparência.

Com este breve ensaio busquei dar mostras do modo como a abordagem da materialidade de Daniel Miller me ajudou a avançar em minhas próprias teorizações. Penso que a longevidade desse diálogo pode ser atribuída à possibilidade de articulação que as proposições de Miller oferecem com outros autores e formulações que, por caminhos distintos, tiveram por interesse analítico e conceitual as coisas. Talvez tenha sido justamente o caráter humilde que as coisas findaram por adquirir em minha própria pesquisa a garantia desse diálogo profícuo.

Recebido em I3/4/2020 | Revisto em 21/9/2020 | Aprovado em I9/Io/2020

Mylene Mizrahi é antropóloga, com mestrado e doutorado no PPGSAIFCS-UFRJ. Atualmente é professora do Departamento de Educação e do Programa de Pós-Graduação em Educação da PUC-Rio. É autora de A estética funk carioca: criação e conectividade em Mr. Catra e de Figurino funk: roupa corpo de dança em um baile carioca, organizadora de Deseducando a educação: mente, materialidade, metáfora. Publicou também artigos e capítulos em periódicos e coletâneas. Seus interesses de pesquisa incluem subjetivação artística, formas expressivas, arte e educação, estéticas corporais, circulação pela cidade, articulados a raça e gênero. 


\section{NOTA}

I Iniciei essa discussão em outra ocasião (Mizrahi, 20I6) e a levo adiante em artigo que se encontra em elaboração.

\section{REFERÊNCIAS BIBLIOGRÁFICAS}

Bourdieu, Pierre. (1984). Distinction. London: Routledge and Kegan Paul.

Butler, Judith. (1993). Bodies that matter: on the discursive limits of sex. London: Routledge.

Gell, Alfred. (1998). Art and agency: an anthropological theory. Oxford: Oxford University Press.

Henare, Amira; Holbraad, Martin \& Wastell, Sari. (2007). Introduction: thinking through things. In: Thinking through things: theorizing artefacts ethnographically. London/New York: Routledge, p. I-3I.

Ingold, Tim. (2012). Trazendo as coisas de volta à vida: emaranhados criativos num mundo de materiais. Horizontes Antropológicos, I8/37, p. 25-44.

Lagrou, Els. (2007). A fluidez da forma: arte, alteridade $e$ agência em uma sociedade amazônica (Kaxinawa, Acre). Rio de Janeiro: Topbooks.

Latour, Bruno. (2005). Reassembling the social. Oxford: Oxford University Press.

Lévi-Strauss, Claude. (I989). O pensamento selvagem. Campinas: Papirus.

Miller, Daniel (org.). (2005). Materiality. London: Duke University Press.

Miller, Daniel. (1987). Material culture and mass consumption. Oxford: Basil Blackwell.

Miller, Daniel \& Woodward, Sophie. (2007). Manifesto for a study of denim. Social Anthropology/Anthropologie Sociale I5/3, p. 335-35I.

Mizrahi, Mylene. (2019a). As políticas dos cabelos negros: estética, relacionalidade e dissidência no Rio de Janeiro. Mana, 25, p. 457-488.

Mizrahi, Mylene. (2019b). Figurino funk: roupa, corpo e dança em um baile carioca. Rio de Janeiro: 7Letras. 
Mizrahi, Mylene. (2018). O Rio de Janeiro é uma terra de homens vaidosos: mulheres, masculinidade e dinheiro junto ao funk carioca. Cadernos Pagu, 52.

Mizrahi, Mylene. (2016). Produzindo estilo negociando sentidos: arte, mercado e criatividade junto ao funk carioca. Antropolítica, 40, p. 252-279.

Mizrahi, Mylene. (2015). Cabelos ambíguos: beleza, poder de compra e 'raça' no Brasil urbano. Revista Brasileira de Ciências Sociais, 30/89, p. 3I-45.

Mizrahi, Mylene. (20I4). A estética funk carioca: criação e conectividade em Mr. Catra. Rio de Janeiro: 7Letras.

Mizrahi, Mylene. (20I2). Cabelos como extensões: relações protéticas, materialidade e agência na estética funk carioca. Textos Escolhidos de Cultura e Arte Populares, 9/2, p. I37-I57.

Mizrahi, Mylene. (20II). Brazilian jeans: materiality, body and seduction at a Rio de Janeiro's Funk Ball. In: Miller Daniel \& Woodward, Sophie (orgs.). Global Denim. Oxford: Berg.

Mizrahi, Mylene. (2007). Indumentária funk: a confrontação da alteridade colocando em diálogo o local e o cosmopolita. Horizontes Antropológicos, I3/28, p. 231-262.

Mizrahi, Mylene. (2003). A influência dos subúrbios na moda da Zona Sul. Relatório de Pesquisa. Universidade Estácio de Sá.

Sahlins, Marshall. (2003). La pensée bourgeoise. In: Cultura e razão prática. Rio de Janeiro: Jorge Zahar Editor.

Strathern, Marilyn. (I99I). Partial connections. Lanham: Altamira Press. 
I056

\section{O QUE A "HUMILDADE DOS OBJETOS" PODE NOS DIZER SOBRE A BELEZA NO RIO DE JANEIRO: NOTAS SOBRE UMA TRAJETÓRIA DE PESOUISA}

\section{Resumo}

Neste texto discorro sobre a relação entre minha trajetória acadêmica e conceitual e a teoria, obra e trajetória de pesquisa de Daniel Miller. A partir de trabalho de campo junto ao funk carioca, com ênfase em sua dimensão estética e nas materialidades que o compõem, elaboro sobre a noção de "humildade dos objetos" e exploro o rendimento que as coisas "ubíquas" podem oferecer para a pesquisa em ciências sociais. Trago à tona a generosidade analítica e afetiva que marca minha interlocução com Miller e revisito o período correspondente ao doutorado-sanduíche, em Londres sob a supervisão do antropólogo inglês. Retomo, ainda que brevemente, as muitas teorias da materialidade que acionei nesse processo e que sigo explorando em meu percurso intelectual e acadêmico.

\section{WHAT THE "HUMILITY OF OBJECTS" CAN TELL US ABOUT BEAUTY IN RIO DE JANEIRO: NOTES ON A RESEARCH TRAJECTORY}

\footnotetext{
Abstract

I discuss the relationship between my academic and conceptual trajectory and Daniel Miller's theory, work and research trajectory. Departing from my fieldwork within funk carioca - Brazilian electronic music - mainly focused on its aesthetic dimension and the materialities, I dell upon the notion of "humility of objects" and explore the potentialities that "ubiquitous" things offer for research in Social Sciences. I bring out the analytical and affective generosity that marks my interlocution with Miller and revisit the period I spent in London to carry on my part of $\mathrm{PhD}$ research, under his supervision. I return briefly to different theories of materiality that I explored and continue to explore in my intellectual and academic path.
}

\section{Palavras-chave}

Humildade dos objetos; ubiquidade; funk carioca; cabelos; moda.

\section{Keywords}

Humility of objects;

ubiquity;

funk carioca;

hair;

fashion. 